\section{Some evidence for a visual slant averaging mechanism}

\author{
WILLIAM D. GROMAN and ROBERT W. WORSHAM \\ Virginia Commonwealth University, Richmond, Va. 23220
}

It was hypothesized that when two surfaces at different angles of slant were presented stereoscopically, the resulting percept would be.a single slanted surface seen at an angle equal to the mean slant of the stimulus objects. Fifteen Ss were tested on the Groman binocular disparator under 15 different conditions of disparity, ranging from . 20 deg to $+20 \mathrm{deg}$. Ten judgments were made for each condition in a random order. The stimulus cards were two $3 \times 4$ in. white cards ruled into $1 / 2$-in. squares. Each exposure was $2 \sec$ in duration. Following exposure $\mathrm{E}$ manipulated a test card until $\mathrm{S}$ indicated that it was at the same angle as the preceding perceived slant. The results strongly supported the hypothesis. They were discussed in terms of a gradient theory of slant perception and a neurophysiological averaging mechanism.

Gibson's gradient theory (1950a) states that outlines, texture density, binocular disparity, and monocular parallax all function as higher-order relational stimuli for slant perception. In distinguishing between monocular depth perception and stereopsis, there has been some implication that binocular disparity may have been overemphasized as a cue for depth (Gibson, 1950b). Slant perception is central to Gibson's theory, and veridical space perception is said to depend on it. However, in defining the stimulus as relational (gradients), Gibson differs from earlier theorists, who regarded the stimulus as a static element of the distal source (Epstein \& Park, 1964; Flock, 1964).

Clark, Smith, \& Rabe (1956) found that when outline convergence was the only cue, perceived slant was far better than texture gradient alone. According to these writers, binocular disparity is relatively unimportant in slant perception.

Ogle's results (1953) are inconsistent with those of Clark, Smith, and Rabe. In Ogle's study depth perception closely approached veridicality with binocular disparity as the only cue.

In normal vision, each eye views a surface at a somewhat different slant, but a single fused slanted surface is perceived. We became interested in whether or not a systematic relationship might exist between the angle of perceived fused slant and the two component angles given by the line of regard of each eye. It was hypothesized that an averaging mechanism exists which uses equally the two different sets of slant information arriving at each eye. This idea is functionally and logically plausible since "centering" of the fused slant would tend toward a veridical perception of the orientation of the head vis-a-vis the surface looked at. In looking at a parallel-frontal surface, the right-eye information alone indicates a right wall wall. Both of these are incorrect since orientation is actually to a parallel-frontal wall. It seems an averaging must exist. or one could never perceive a parallel-frontal surface binocularly.

An earlier study (Groman, 1962) yielded evidence for such an averaging mechanism. Under monocular viewing conditions, abduction and adduction of an eye respectively yielded larger and smaller perceived slants for the same slanted surface. Under binocular conditions, however, when one eye is abducted and the other is adducted, the result is that these differences will cancel one another, or "average out."

Because of differences such as sighting dominance, acuity dominance, and other visual aberrations, it is not at once apparent how an averaging mechanism would function. For veridical orientation and localization of a surface, however, such eye differences should be discounted. It was specifically hypothesized, the refore, that the binocularly seen slant of a surface would be the arithmetic mean of the slants presented to each eye. It follows from this that sighting dominance would not affect perceived slant.

\section{SUBJECTS}

Fifteen college students, seven males (median age 25) and eight females (median age 21) served as Ss. None showed defects in binocular vision on testing with the Keystone Visual Survey Telebinocular (Keystone View Co., Meadville, Pa.).

\section{APPARATUS}

The Groman Continuous Binocular Disparator (Groman, 1964) was used. Two $3 \times 4$ in. cards ruled in $1 / 2$-in.-interval black lines horizontally and vertically were centered upright on each stimulus carrier and viewed through a prism stereoscope. Polar graph paper below each carrier permitted accurate selection of angle of (right side nearer), and the left eye a left slant. Following inspection $S$ rotated his chair 90 deg to view the test object (same as one of the inspection cards). Chin rests were used and illumination was by fluorescent lamps above the apparatus.

\section{DESIGN}

Before proceeding, positive and negative slant, and positive and negative disparity will be defined. Rotation of a parallel-frontal plane about its vertical axis clockwise (right side nearer, right wall) is designated positive slant, rotation counterclockwise is designated negative slant. Disparity is defined as right-eye slant minus left-eye slant. If $-30 \mathrm{deg}$ is seen by the right eye and $-10 \mathrm{deg}$ by the left eye, then disparity equals $-30 \mathrm{deg}-(-10 \mathrm{deg})$, or -20 deg.

The two independent variables were slant and disparity. There were three degrees of slant $(-20,0$, and $+20 \mathrm{deg})$ and five different disparities $(-20,-10,0,+10$, and $+20 \mathrm{deg}$ ), forming 15 treatment conditions. All Ss served in all 15 conditions, receiving 10 trials per treatment, a total of 150 trials each. For each $\mathrm{S}$ a unique randomized trial order was used.

\section{PROCEDURE}

For classification, each $S$ was given a simple sighting dominance test consisting of sighting a target through a $1 / 4$-in. hole in an $8 \times 10$ in. card five times. $S$ was then tested for binocular vision. Seated comfortably, $S$ was shown the test stimulus set at 0 deg and then the inspection stimuli. The prism stereoscope was adjusted until $S$ stated that he saw a card that looked exactly the same as the test card. E then read the instructions.

The 2-sec exposure used minimized a known adaptation effect toward the parallel frontal for prolonged viewing (Bergman \& Gibson, 1959), but allowed ample time for $S$ to estimate the slant. Starting position of the test card was alternated between extreme positive and extreme negative slant. $E$ did not see the dial during adjustment of the test card, but noted the perceived slant after each trial. S rested $5 \mathrm{~min}$ after the 50 th and 100 th trials.

\section{RESULTS}

The mean perceived siants for all conditions are given in Table 1. The average deviation from the predicted mean slants was -2.7 deg. Note that all the means in Column 5 deviate in a negative direction from the predicted slant. This is attributable to a systematic error arising from a slight misalignment of the apparatus. Inspection of the raw data also suggests this interpretation since the great majority of raw scores deviate from prediction in the negative direction.

A Pearson I calculation between 
Table 1

Treatment Conditions, Predicted Perceived Slant. Perceived Slant, Disparities. and Variances for the Five Disparities

\begin{tabular}{|c|c|c|c|c|c|c|}
\hline & $\begin{array}{l}\text { Right } \\
\text { Eye } \\
\text { (Deg) }\end{array}$ & $\begin{array}{c}\text { Left } \\
\text { Eye } \\
(\text { Deg) } \\
\end{array}$ & $\begin{array}{c}\text { Disparity } \\
\text { (Deg) }\end{array}$ & $\begin{array}{c}\text { Predicted } \\
\text { Perceived } \\
\text { Slant } \\
\text { (Deg) } \\
\end{array}$ & $\begin{array}{c}\text { Mean } \\
\text { Perceived } \\
\text { Slant } \\
\text { (Deg) }\end{array}$ & $\begin{array}{c}\text { Variance* } \\
\text { (Deg) }\end{array}$ \\
\hline $\begin{array}{l}1 \\
2 \\
3 \\
4 \\
5\end{array}$ & $\begin{array}{l}-30 \\
-25 \\
-20 \\
-15 \\
-10\end{array}$ & $\begin{array}{l}-10 \\
-15 \\
-20 \\
-25 \\
-30\end{array}$ & $\begin{array}{r}-20 \\
-10 \\
0 \\
+10 \\
+20\end{array}$ & $\begin{array}{l}-20 \\
-20 \\
-20 \\
-20 \\
-20\end{array}$ & $\begin{array}{l}-22.1 \\
-23.1 \\
-21.9 \\
-23.7 \\
-23.8\end{array}$ & $\begin{array}{l}51.0 \\
12.1 \\
10.3 \\
24.1 \\
39.3\end{array}$ \\
\hline $\begin{array}{r}6 \\
7 \\
8 \\
9 \\
10\end{array}$ & $\begin{array}{r}-10 \\
-5 \\
0 \\
+5 \\
+10\end{array}$ & $\begin{array}{r}+10 \\
+5 \\
0 \\
-5 \\
-10\end{array}$ & $\begin{array}{l}0 \\
0 \\
0 \\
0 \\
0\end{array}$ & $\begin{array}{l}0 \\
0 \\
0 \\
0 \\
0\end{array}$ & $\begin{array}{l}-1.4 \\
-1.7 \\
-2.6 \\
-2.6 \\
-3.1\end{array}$ & $\begin{array}{l}10.3 \\
10.3 \\
10.3 \\
10.3 \\
10.3\end{array}$ \\
\hline $\begin{array}{l}11 \\
12 \\
13 \\
14 \\
15\end{array}$ & $\begin{array}{l}+10 \\
+15 \\
+20 \\
+25 \\
+30\end{array}$ & $\begin{array}{l}+30 \\
+25 \\
+20 \\
+15 \\
+10\end{array}$ & $\begin{array}{r}-20 \\
-10 \\
0 \\
+10 \\
+20\end{array}$ & $\begin{array}{l}+20 \\
+20 \\
+20 \\
+20 \\
+20\end{array}$ & $\begin{array}{l}+18.0 \\
+17.5 \\
+16.0 \\
+16.7 \\
+17.4\end{array}$ & $\begin{array}{l}51.0 \\
12.1 \\
10.3 \\
24.1 \\
39.3\end{array}$ \\
\hline
\end{tabular}

*The rariance show' is for the pooled dato for all conditions of the corresponding disparity.

perceived slant and predicted slant for the 15 treatments yielded an $r$ of .94 , $\mathrm{p}<.001$.

Table 1 also shows that the variance increases in both directions as disparity deviates from zero. A possible explanation is discussed below.

Differences among disparity levels were examined by means of Friedman's nonparametric analysis of variance. The statistic $\left(\mathrm{X}_{\mathrm{r}}^{2}\right)$ was $5.00, \mathrm{p}<.30$, which was not significant.

Right-eye-dominant Ss were compared with left-eye-dominant Ss for the two extreme disparity conditions ( -20 and $+20 \mathrm{deg}$ ), since these conditions are where eye dominance would (if operating) exert most effect. Two $t$ tests showed no significance at these two levels of disparity, and differences at the other levels were of even lesser magnitude.

\section{DISCUSSION}

The correlation reported clearly supports the hypothesized slant-averaging mechanism. Increase in variance of judgment as disparity deviates from zero in both directions indicates a loss of precision in slant perception as disparity becomes greater. Probably 20-deg disparity approaches the limit of binocular fusion, thus increasing the likelihood of greater variance. That none of the disparity conditions differed significantly from the zero-disparity condition is a further indication of the tendency toward binocular slant averaging.

That sighting dominance had no significant effect upon perceived slant follows logically when the functional properties of the binocular system are considered. For, if the input to either eye were to dominate the input to the other eye, then the functional significance of binocular vision, i.e., accurate localization, would be defeated. This pertains, of course, only to normal conditions of disparity, when the limits of binocular fusion are not exceeded.

An interesting contradiction of visual information arises under conditions of negative disparity. For example, consider the condition where disparity equals $-20 \mathrm{deg}$ (right eye presented with $-30 \mathrm{deg}$, left eye presented with $-10 \mathrm{deg}$, average equals $-20 \mathrm{deg}$ ). The binocular information contained in this condition is shown in Fig. 1.

Based on outline convergence alone, the information is that of a negative slant (left wall). The results yielded a mean perceived slant for this condition of $-22.1 \mathrm{deg}$, which approximates the average of -30 and -10 deg. However, based on disparity gradient alone, the $\mathrm{S}$ should have perceived a positive slant (right wall). This is so because the double images to the right of the fixation point (assumed to be the center of the card for this example) are crossed double images. Crossed double images presumably carry the information of "nearer than fixation point." To the left of the fixation point, double images are uncrossed, presumably carrying the information of "farther than fixation point." The results indicate that there was not even a tendency for perceived slant toward the direction indicated by crossed and uncrossed double images when the conflict of information occurred. Apparently the information "crossed vs uncrossed" double images played no part in the perception of slant under the experimental conditions. This interpretation is consistent with Clark, Smith, \& Rabe (1956), who found outline convergence alone to be a much more potent cue for slant perception than a texture gradient pattern (which would give rise to double images). Smith (1964) has also found that outline convergence has a marked and reliable effect on visual slant, but that texture gradients do not. Freeman's (1966) report that even large stimuli without surface texture have very small slant thresholds when the task is to detect a deviation from the parallel-frontal also points to the importance of outline convergence. These cited studies, together with the present data, support the assumption of the relative dominance of outline convergence as a cue for visual slant. This conclusion is functionally logical when one considers the conditions in the following way. In free viewing, the eyes are constantly changing their point of fixation. Each time the point of fixation is changed, the double-image pattern of the previous fixation is lost, as is the gradient of disparity associated with that fixation point. In other words, there is great change in double images and disparity gradients in normal vision; however, there is great stability in the outline convergence of objects impinging on the retinas. Outline form of objects does not change with changes in fixation. Functionally, it would be more efficient for the visual system to use the more stable outline convergence for slant perception and to ignore the more complex, and not always correlated, information.

In all probability, cues for slant perception are utilized in a type of hierarchy. This hierarchy might manifest itself under conditions of diminished or contradictory information. In Ogle's experiment (1953), double images were the only cues available, and the information

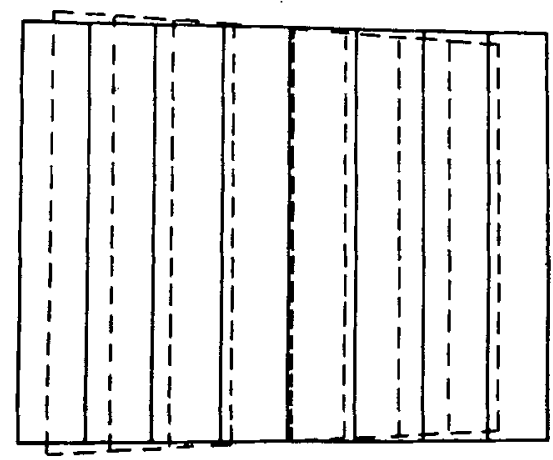

Fig. 1. Overlapping binocular information when right eye receives $-30 \mathrm{deg}$ left slant and left eye receives -10 deg slant. For simplicity, only vertical lines are shown. Disparity gradient conflicts with outline convergence. 
seems to have been appropriately used. If other cues in the hierarchy had been available. perhaps the double-image information would have been discarded.

This idea was supported in an informal experiment in which the authors served as Ss. The binocular disparator was used to present white surfaces which had been ruled either horizontally or vertically. A reduction screen prevented using the outline of surfaces as a slant cue. It was found that viewing the vertically lined surfaces, which provided double-image information, analogous to Ogle's condition, resulted in almost total lack of slant perception or an occasional ambiguous slant. Viewing the horizontally lined surfaces resulted in an immediate and veridical perception of slant. Thus, it appears that line convergence was the major stimulus for the perception of slant in this situation.

\section{REFERENCES}

BERGMAN, R., \& GIBSON, J. J. The negative after-effect of the perception of a surface slanted in the third dimension. American Journal of Psychology, 1959, 72, 364-374.

CLARK, W. C., SMITH, A. H., \& RABE, A. Retinal gradients of outline distortion and binocular disparity as stimuli for slant. Canadian Journal of Psychology, 1956, 10, $77-81$.

EPSTEIN, W.. \& PARK, J. Examination of Gibson's psychophysical hypothesis. Psychological Bulletin. 1964, 62, 180-196.

I:LOCK, H. R. Three theoretical views of slant perception. Psychological Bulletin, 1964.62, $110-121$.

FREEMAN, R. B., JR. Absolute threshold for visual slant: The effect of stimulus size and retinal perspective. Journal of Experimental Psychology, 1966, 71.170-176.

GIBSON, J. J. The perception of visual surfaces. American Journal of Psychology, 1950a, 63. 367.384 .

GIBSON, J. J. The perception of the visual world. Boston: Houghton-ilifflin, 1950b.

GIBSON, J. J. The concept of the stimulus in psychology. American Psychologist. 1960, 16, 694-703.

GROMAN, W. D. Orientation, stimulus pattern. and head-eye position as determinants of cognitive and experiential aspects of perceived slant. Unpublished doctoral dissertation. Duke University, 1962.

GROMAN, W. D. An apparatus for presenting continuously varying binocularly disparate views of an apparently single object. Quarterly Journal of Experimental Psychology, 1964. 16, 184-186.

OGLE, K. N. Precision and validity of stereoscopic depth perception from double images. Journal of the Optical Society of America, 1953, 43, 906-913.

SMITH, A. H. Judgment of slant with constant outline convergence and variable surface texture gradient. Perceptual \& Motor Skills, $1964,18,869-875$.

\title{
A new coordination test of visual-motor deprived visually experienced cats*
}

\author{
STEPHEN E. FISH and JOHN S. ROBINSON \\ Brain-Behavior Research Center, Eldridge, Calif. 95431
}

Cats with extensive binocular visual experience but with only monocular visual-motor experience were found to have visual-motor deficits in both deprived and experienced eyes when tested on a new apparatus requiring smooth negotiation of a series of barriers.

Currently used methods for measuring visual-motor behavior in immature, deprived, or lesioned animals are still relatively primitive. Simple observation of obstacle avoidance during free movement and the relatively crude visual placing response test are frequently used. Recently Hein \& Held (1967) described a version of the latter modified to measure behavior requiring more precise visual guidance.

The barrier apparatus described here allows one to make qualitative observations and objective measurements of the complex movements required in the cat's visually guided locomotion among obstacles. The task can be made sensitive enough to detect differences between a normal S's eyes. The apparatus will be described and its use illustrated by showing

*This work was supported in part by Grants MH 08832 and HD 05317 from the National Institutes of Health, U.S. Public Health Service.

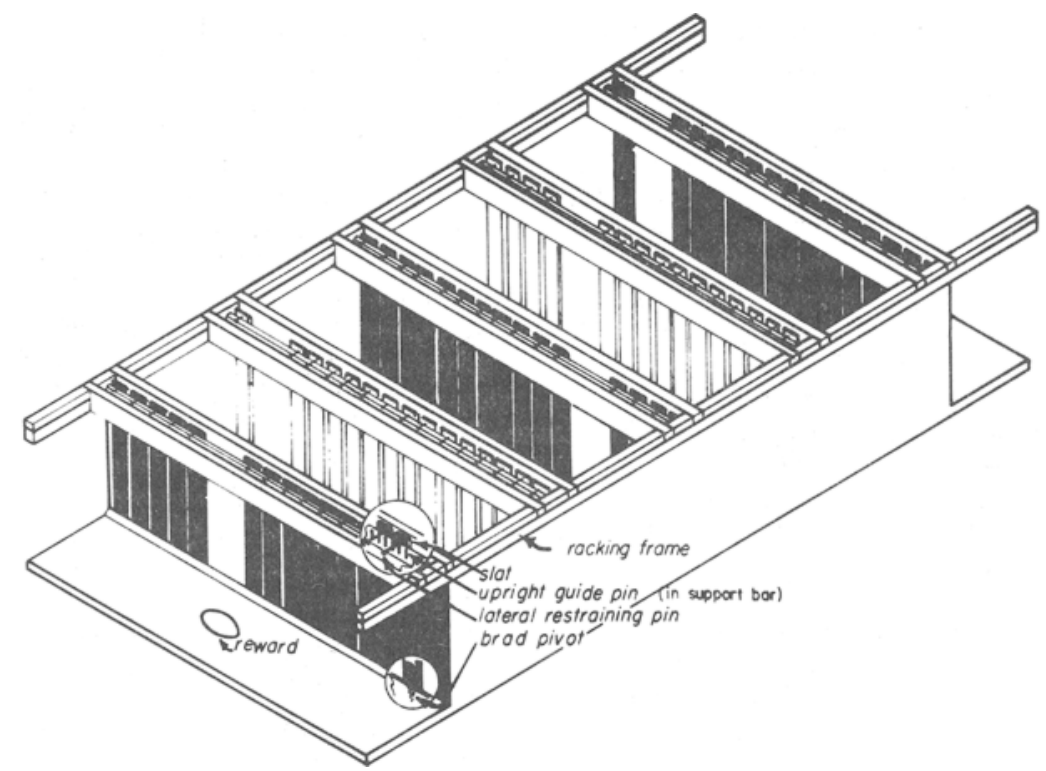

Fig. 1. Barrier apparatus for testing visual-motor coordination. The $\mathbf{S}$ must use visual cues in finding the most direct path to the reward and in adjusting movements so that passage through the openings is smooth. how it was adapted to study the effects of providing Ss with visual experience while preventing them from using it in getting about.

\section{BARRIER APPARATUS FOR MEASURING VISUAL-MOTOR COORDINATION}

The five 18-in.-high barriers in the apparatus illustrated in Fig. 1 are 18 in. apart and have 14 slats. A racking frame which rests on side pieces can be pushed or pulled from either end to set all the slats so that they lean one way or the other. The slat guide device is shown in the insert. The large nail "lateral restraining pin" in the top of the slat and the "brad pivot" in the bottom allow the slat to rock back and forth but prevent sideways movement. The "support bar" limits the fall of the slats: Tipped forward the slats come to rest against the bar; tipped 